\title{
Breeding ecology of Styan's Bulbul Pycnonotus taivanus in Taiwan
}

\author{
MINNA J. HSU' \& YAO-SUNG LIN ${ }^{2}$ \\ ${ }^{1}$ Department of Biology, National Sun Yat-sen University, Kaohsiung 80424, Taiwan, Republic of China \\ ${ }^{2}$ Department of Zoology, National Taiwan University, Taipei, Taiwan, Republic of China
}

\begin{abstract}
The breeding ecology of Styan's Bulbul Pycnonotus taivanus, an endemic species in Taiwan, was studied in Kenting, Taiwan. The duration of the breeding season of Styan's Bulbul stretched from March to July in 1983. The average clutch size was 3.3 eggs $(n=34)$, and hatching success was $60 \%$. The average number of nestlings at hatching was 2.7 per clutch, and $73 \%$ of the young fledged. Styan's Bulbuls selected their nest sites among dense vegetation. In the study area, $75 \%(n=84)$ of nests were found in the Indiapoon Beautyleaf tree Calophyllum inophyllum, which had a relative vegetation density of only $33.5 \%$. Factor analysis was used to analyse 13 nest-site characteristics of 63 nests, and five factors accounted for $69 \%$ of the variation.
\end{abstract}

Styan's Bulbul Pycnonotus taivanus is an endemic species restricted to Taiwan. About a century ago, this species was found only in a restricted geographic range at the southernmost tip of Taiwan (La Touche 1895, Ogilvie-Grant \& La Touche 1907). However, over the last few decades, Styan's Bulbul has become common on the east coast of Taiwan (Hachisuka \& Udagawa 1951, Hsu \& Lin 1993). The other extant species, the Chinese Bulbul Pycnonotus sinensis, has been regarded as ecologically equivalent to Styan's Bulbul (Hachisuka \& Udagawa 1951), and it occurs in the western and northern parts of Taiwan (Hsu \& Lin 1993). The distributions of the two species narrowly overlap in Fengkang in the southwest and recently also in Hualian City in the east (Severinghaus \& Blackshaw 1976, Hsu \& Lin 1993). Although Styan's and Chinese Bulbuls are now common in Taiwan, habitat alterations and urbanization threaten their survival throughout their range today, and still very little is known about their breeding biology, ecology and behaviour in Taiwan. To date, only descriptions of breeding and feeding activities of the Chinese Bulbul (Tze \& Mong 1977, Severinghaus 1978, Hsu \& Lin 1994) and the morphology of hybridization between Chinese and Styan's Bulbuls (Hsu \& Lin 1993) have been reported. This paper describes for the first time the breeding ecology and nest site selection in Styan's Bulbul.

\section{METHODS}

The field studies were carried out between September 1982 and May 1984 at Kenting National Park $\left(21^{\circ} 90^{\prime} \mathrm{N}\right.$, $120^{\circ} 80^{\prime} \mathrm{E}$ ) in southern Taiwan. The climate of the park is tropical, with dry winters and humid summers. The mean monthly temperatures range from $29.8^{\circ} \mathrm{C}$ (July) to $21.5^{\circ} \mathrm{C}$ (January), without a cold winter (Wang 1980). Precipitation is usually concentrated between May and August, while the dry season lasts for about 9 months. Dominant tree species at the study site are Swamp Oak Casuarina equisetifolia, Mountain Oak Casuarina montana, Indiapoon Beautyleaf Calophyllum inophyllum and Taiwan Acacia Acacia confusa. Two shrub species, the Common Lantana Lantana camara and the Jamaica False Valerian Stachytarpheta jamaicensis, are common at the study site and provide major food resources (fruits or flowers) for Styan's Bulbul.

Data on the breeding biology of Styan's Bulbul were collected by direct observation. Nests and nest sites were routinely checked, with minimal disturbance to the birds, to record information on the date of egg laying, length of incubation, date of hatching and development and survival of the young. We also measured and marked the eggs to analyse the relationships between size, egg-laying sequence and hatching sequence. Nests of bulbuls were measured to record the inner and outer diameters, width, height (from the opening to the bottom of nest) and depth (the vertical distance from the opening to the nest base).

The point-quarter method (Noon 1981) was used to quantify vegetation density at nest sites and in the area generally by the selection of random points (giving relative density, relative dominance. frequency and relative frequency of trees). Within the study area, 150 random points were selected (one each in 20-m $\times 40-\mathrm{m}$ units) along transects following a northwest-southeast direction. Vegetation analyses of 63 nest sites were made by the point-quarter method with the nest in the centre. Details of methods used to measure 13 nest-site characteristics are described in the Appendix. The nest site vegetation was categorized at four levels: $>6 \mathrm{~m}, 3-6 \mathrm{~m}, 1-3 \mathrm{~m}$ (shrubs) and ground level (grasses). Analyses of nest sites and the vegetation were made by multivariate and factor analyses (Morrison 1976). From a correlation matrix of 13 nest-site characters measured for 63 nests, factor loadings were calculated by principal component analysis using SAS (SAS Institute Inc. 1985). 


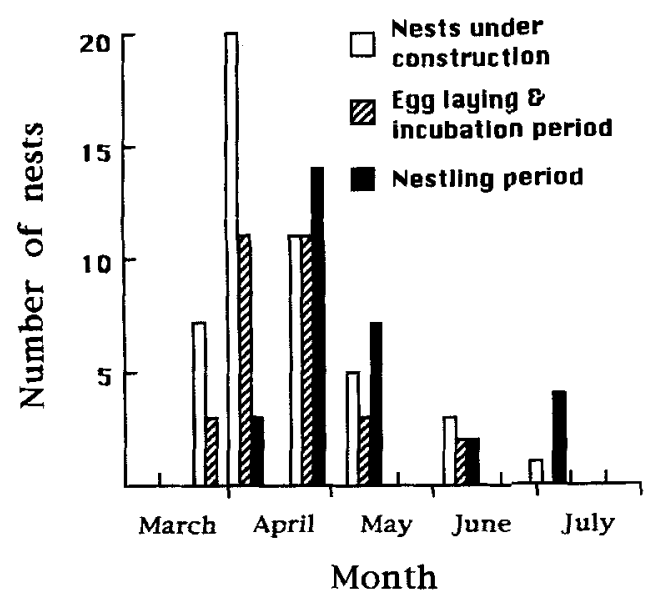

Figure 1. Chronograph of the Styan's Bulbul breeding cycle in Kenting, Taiwan.

\section{RESULTS}

\section{Egg, clutch and nestling}

The average clutch size of Styan's Bulbul was 3.3 eggs ( $n$ $=34$ ), with $66 \%$ of clutches with three and $23 \%$ of clutches with four eggs. Eggs were laid in the early morning and at about 24 -h intervals. The mean egg size was $21.80 \pm$ $1.35 \mathrm{~mm} \times 15.66 \pm 0.64 \mathrm{~mm}(n=79)$. Eggs varied in size within a clutch and between clutches depending on the sequence in laying and size of the clutch. The widths of eggs became significantly larger from the first to the last $\left(F_{2.8}\right.$ $=5.25, P<0.05)$. The mean egg length in four-egg clutches was significantly less than in three-egg clutches $\left(F_{4.8}=\right.$ 6.63, $P<0.05$ ), but the breadth did not differ significantly. The mean size of a territory was $624 \mathrm{~m}^{2}$. The closest distance recorded between two active nests was $5 \mathrm{~m}$ because the nests were not always in the centre of territories.

Incubation started when the last egg was laid. The mean incubation period was 11.4 days (range 11-12 days) and the hatching success was $60 \%(n=53)$. The nestling period lasted about 9-10 days. In 1983, 70\% of the nestlings occurred during late April and mid-May (Fig. 1). The average number of nestlings per brood at hatching was $2.7(n=$ 21 ), and $73 \%$ of the young successfully fledged. The body mass of nestlings increased from $2 \mathrm{~g}$ at hatching to $27 \mathrm{~g}$ when 15-day-old fledglings. Fledglings were seen in the parents' territories until they were about 25 days old, and their parents fed them during this period.

\section{Nest site selection}

Most of the cup-shaped nests were built at the junction of several branches, from $83 \mathrm{~cm}$ to $500 \mathrm{~cm}$ above the ground. The nest was composed of stems, leaves, grasses and, occasionally, plastic materials. The most common shrub in the study area was Lantana camara, with $57 \%$ relative vegetation density, followed by Stachytarpheta jamaicensis. Bulbuls selected their nest sites among dense vegetation, and the den-
Table 1. The nest sites of Styan's Bulbul in different tree species and the relative vegetation density of each tree species at Kenting, Taiwan

\begin{tabular}{|c|c|c|c|}
\hline \multirow[b]{2}{*}{ Tree species } & \multicolumn{2}{|c|}{ Nest sites } & \multirow{2}{*}{$\begin{array}{c}\text { Relative } \\
\text { vegetation } \\
\text { density } \\
(\%)\end{array}$} \\
\hline & No. & $\%$ & \\
\hline Calophyllum inophyllum & 63 & 75 & 34 \\
\hline Gelonium aequoreum & 4 & 5 & 5 \\
\hline Aglaia formosana & 4 & 5 & 3 \\
\hline Macaranga tanarius & 2 & 2 & 1 \\
\hline Liodendron formosanum & 2 & 2 & $<1$ \\
\hline Ficus microcarpa & 2 & 2 & $<1$ \\
\hline Casuarina equisetifolia & 1 & 1 & 11 \\
\hline Artocarpus heterophyllus & 1 & 1 & $<1$ \\
\hline Acacia confusa & 1 & 1 & 11 \\
\hline Terminalia catappa & 1 & 1 & 4 \\
\hline Scolopia oldhamii & 1 & 1 & 2 \\
\hline Buchanania arbarescens & 1 & 1 & $<1$ \\
\hline Euphoria longana & 1 & 1 & $<1$ \\
\hline Total & 84 & 100 & 71 \\
\hline
\end{tabular}

sity of trees surrounding bulbul nests $(n=68)$ was higher (1257/ha) than at random points (756/ha). During 1983 , the majority of the nests were found in Calophyllum inophyllum, and other nests were found in tree species such as Swamp Gelonium Gelonium aequoreum, Formosan Aglaia Aglaia formosana and Macaranga Macaranga tanarius (Table 1). Although $C$. inophyllum was the tree species used most frequently for nesting (density 253/ha), the relative density of C. inophyllum was only $33 \%$. Although Acacia confusa, with a large diameter of the tree trunk at breast height and basal areas, had the highest relative dominance, the bulbuls did not use this species for nest building. These two species and Casuarina spp. comprised $56 \%$ of the tree community. There was no significant difference between the sizes of the 48 nests built in $C$. inophyllum and the 15 nests built in nine other tree species. However, the difference between nest-site characteristics in C. inophyllum $(n=63$; Table 2) and those in other tree groups was statistically significant (Mahalanobis $D^{2}=3.9, T^{2}=44.5, F_{13,49}=2.75, P<0.01$ ).

Principal component analysis revealed that five factors accounted for $69 \%$ of the variation in the data (Table 3 ). The most important factor was the structure of the supporting branches, including number and basal area of these branches, accounting for $18.8 \%$ of the variance. The second most important factor was the nest openness, which accounted for $16.8 \%$ of the variation, while the third most important, accessibility, accounted for a further $13.5 \%$ of the variation.

\section{DISCUSSION}

In tropical and temperate regions, passerine birds generally have two or more broods per breeding season (Oring 1982). 
Tahle 2. Characteristics of 63 nest sites of Styan's Bulbul in Kenting, Taiwan

\begin{tabular}{lcc}
\hline \multicolumn{1}{c}{ Variable } & Mean & s.d. \\
\hline Nest height above ground (cm) & 264 & 85 \\
Tree-nest difference $(\mathrm{cm})$ & 126 & 65 \\
Distance to nearest leaf $(\mathrm{cm})$ & 4.7 & 2.4 \\
Nest position index to canopy & 63 & 24 \\
Distance to main trunk (cm) & 42 & 46 \\
Distance to nearest open space (cm) & 53 & 31 \\
Distance beween supporting branches (cm) & 7.5 & 2.7 \\
Number of supporting branches & 3.9 & 1.1 \\
Basal area of supporting branches (cm $\left.{ }^{2}\right)$ & 5.8 & 11.3 \\
Number of nest-tree trunks & 4.1 & 3.0 \\
Nest-tree basal area (cm $\left.{ }^{2}\right)$ & 112 & 182 \\
Tree density at nest height (no./ha) & 1794 & 1616 \\
Distance to road or building (m) & 18 & 13 \\
\hline
\end{tabular}

Styan's Bulbul had, on occasion, two successful broods per breeding season, but the Chinese Bulbuls on the mainland had two or three (Cheng 1963) and even four broods each year (Rutgers 1969). However, Hsu and Lin (1994) studied Chinese Bulbuls in Taipei and found only a few pairs were able to successfully rear a second brood.

Precipitation and food may have been factors for the initiation of the breeding season of Styan's Bulbul, as reported for Whitecheeked Bulbul Pycnonotus leucogenys (Ali \& Ripley 1971). The 9-month-long dry season at our study site limits the growth of vegetation and the number of insects and probably restricts the breeding of birds.

Incubation in Styan's Bulbul usually started when the last egg was laid, which decreased the duration of hatching within a brood. Nevertheless, in both Styan's and Chinese Bulbuls, a 12-24-h hatch difference within a brood existed
(Hsu \& Lin 1994). The average incubation periods for several species of bulbuls range from 11 to 14 days (Brosset $1981 \mathrm{a})$. The incubation period of Styan's Bulbul (11-12 days) is similar to that of the Lesser Icterine Greenbulbul Phyllastrephus icterinus (Brosset 1981a) and is slightly shorter than that of the Chinese Bulbul (11-13 days; Hsu \& Lin 1994).

Styan's Bulbul is about $1.5 \mathrm{~g}$ heavier than the Chinese Bulbul (Hsu \& Lin 1993). The clutch size of Styan's Bulbul observed in our study (3.3 eggs) was also larger than that reported for the Chinese Bulbul (2.9 eggs, $n=8$; Hsu \& Lin 1994). However, the Chinese Bulbuls' eggs were larger $(22.46 \mathrm{~mm} \times 16.14 \mathrm{~mm}$, fresh mean mass $=3.04 \mathrm{~g}, n=$ 20 ) and their nests were slightly larger than those of Styan's Bulbul (Hsu \& Lin 1994). The eggs in three-egg clutches were significantly smaller in Styan's Bulbuls than Chinese Bulbuls $\left(F_{2.6}=4.6, P<0.05\right)$. The majority of the Styan's Bulbul fledglings were seen during late April to mid-May. In India, the fledglings of Redvented Bulbuls Pycnonotus cafer were found mainly between February and May, White cheeked Bulbuls from March to September and Redwhiskered Bulbuls Pycnonotus jocosus from February to August (Ali 1979).

Styan's Bulbuls built nests in dense vegetation offered by different tree species (Table 1), behaviour similar to that of several other species of bulbuls (Brosset 1981a-c). The dense vegetation, which restricts visibility, probably provided camouflage for the nests in the high-quality environment of Styan's Bulbuls. In species such as Dickcissels Spiza americana (Zimmerman 1971) and Red-winged Blackbirds Agelaius phoeniceus, (Albers 1978) nest sites and territories were selected in dense vegetation. Moreover, feral Cats Felis catus and Red-bellied Tree Squirrels Callosciurus erythraeus were abundant in the study area, and predation by cats and squirrels might have influenced the selection of dense vegetation for nest sites by Styan's Bulbuls. Brosset (1981a-c)

Table 3. Factor analysis of Styan's Bulbul nest-site characters

\begin{tabular}{|c|c|c|c|c|c|}
\hline \multirow[b]{2}{*}{ Variable } & \multicolumn{5}{|c|}{ Factor } \\
\hline & 1 & 2 & 3 & 4 & 5 \\
\hline Nest height above ground & 0.02 & -0.20 & $-0.77^{*}$ & 0.15 & -0.03 \\
\hline Tree-nest difference & -0.07 & $0.87^{*}$ & 0.08 & -0.07 & -0.01 \\
\hline Distance to nearest leaf & -0.13 & 0.07 & 0.29 & $0.81^{*}$ & -0.20 \\
\hline Nest position index to canopy & -0.02 & -0.20 & 0.12 & -0.07 & $0.87^{*}$ \\
\hline Distance to main trunk & 0.14 & $0.85^{*}$ & $0.00+$ & 0.28 & -0.12 \\
\hline Distance to nearest open space & 0.17 & 0.39 & -0.30 & 0.49 & $0.56^{*}$ \\
\hline Distance between supporting branches & $-0.92^{*}$ & 0.01 & -0.02 & 0.13 & $0.00+$ \\
\hline Number of supporting branches & $0.90^{*}$ & 0.07 & 0.08 & -0.05 & 0.12 \\
\hline Basal area of supporting branches & $0.74^{*}$ & 0.01 & -0.11 & 0.18 & -0.09 \\
\hline Number of nest-tree trunks & -0.07 & 0.14 & $0.53^{*}$ & -0.01 & 0.43 \\
\hline Nest-tree basal area & 0.10 & 0.08 & -0.25 & $0.74^{*}$ & 0.18 \\
\hline Tree density at nest height & 0.08 & -0.06 & 0.19 & 0.08 & 0.10 \\
\hline Distance to road or building & 0.04 & -0.17 & $0.71^{*}$ & 0.16 & 0.01 \\
\hline
\end{tabular}

* Indicates the component accounts for greater than $25 \%$ of variance of variable: + indicates the value is less than 0.005. 
studied the breeding of 11 species of bulbuls and found that their nests were not concealed but were placed in open situations at heights less than $6 \mathrm{~m}$ above ground level, which is similar to the Styan's Bulbul of Taiwan.

On the basis of nest site selection, food resources and feeding habits. Styan's Bulbuls in Taiwan appear to be generalists, similar to the Chinese Bulbuls (Tze \& Mong 1977. Hsu \& Lin 1994, this study). Other species of bulbuls have successfully invaded different ecological niches in the lowlands and have shown more flexibility in their habitat selection (MacArthur \& Wilson 1967, Morse 1971). The degree of competition between birds can be estimated from comparisons of habitat use (MacArthur 1958, Cody 1978, Noon 1981). However, Styan's and Chinese Bulbuls have an allopatric distribution with a small number overlapping narrowly. Therefore, it is difficult to compare interspecific competition in the use of habitats.

This research was supported by the Ecology Laboratory of the Department of Zoology, National Taiwan University. We thank Drs L. S. Chou, L. Severinghaus and Y. Wang for their encouragement and support during the course of field work and data analysis. We are grateful to Drs G. Agoramoorthy and J. C. Coulson for critically reviewing an earlier version of the manuscript.

\section{REFERENCES}

Albers, P.H. 1978. Habitat selection by breeding Red-winged Blackbirds. Wilson Bull. 90: 103-111.

Ali, S. 1979. The Book of Indian Birds. Bombay: Oxford University Press.

Ali. S. \& Ripley. S.D. 1971. Handbook of the Birds of India and Pakistan. London and Bombay: Oxford University Press.

Brosset, A. 1981a. Evolution divergente des comportements chez deux Bulbuls sympatriques (Pycnonotidae). Alauda 49: 94-111.

Brosset, A. 1981b. Occupation du milieu et structure d'une population du Bulbul forestier Andropadus latirostris (Pycnonotidae). Oiseau 51: 115-126.

Brosset. A. 1981c. La periodicite de la reproduction chez un Bulbul de foret equatoriale Africaine Andropadus latirostris. Terre Vie 35: 109-129.

Cheng, T.H. 1963. China's Economic Fauna: Birds. Paipeng: Chinese Academy of Science.

Cody. M.L. 1978. Habitat selection and interspecific territoriality among the sylviid warblers of England and Sweden. Ecol. Monogr. 48: 351-396.

Hachisuka, M. \& Udagawa, T. 1951. Contribution to the ornithology of Formosa, Parts I and II. Q. J. Taiwan Mus. 3: 187-280.

Hsu, M.J. \& Lin. Y.S. 1993. Morphology, sexual dimorphism and hybridization in Styan's Bulbuls Pycnonotus taivamus and Chinese Bulbuls P. sinensis formosae. Acta Zool. Taiwanica 4: 103-111.

Hsu, M.J. \& Lin. Y.S. 1994. The annual cycle of the Chinese Bulbul Pycnonotus sinensis formosae in Taiwan. Acta Zool. Taiwanica 5: 33-39.

La Touche, J.D. 1895. Notes on South Formosan birds. Ibis 1: 305 338.

MacArthur, R.H. 1958. Population ecology of some warblers of north-eastern coniferous forests. Ecology 39: 599-619.
MacArthur, R.H. \& Wilson, E.O. 1967. The Theory of Island Biogeography. Princeton, N.J.: Princeton University Press.

Morrison, D.F. 1976. Multivariate Statistical Methods. New York: McGraw-Hill.

Morse. D.H. 1971. The insectivorous birds as an adaptive strategy. Ann. Rev. Ecol. Syst. 2: 177-200.

Noon, B.R. 1981. Techniques for sampling avian habitats. In Capen, D.E. (ed.) The Use of Multivariate Statistics in Studies of Wildlife Habitat: Proceedings of a workshop. USDA Forest Service General Technical Report RM-87. Fort Collins, Colo.: Rocky Mountain Forest and Range Experiment Station. 249 pp.

Ogilvie-Grant, W.R. \& La Touche, J.D. 1907. On the birds of the island of Formosa. Ibis 9: 189.

Oring, L.W. 1982. Avian mating systems. In Farner, D.S. \& King, J.R. (eds) Avian Biology, Vol. VI. New York and London: Academic Press.

Rutgers, A. 1969. Birds of Asia. New York: Taplinger Publishing Co.

SAS Institute Inc. 1985. SAS/STAT Guide for Personal Computers, 6th ed. Cary, N.C.: SAS Institute Inc.

Severinghaus, S.R. 1978. Aerial feeding by Asian bulbuls. Ibis 120: 514-516.

Severinghaus, S.R. \& Blackshaw, K.T. 1976. A New Guide to the Birds of Taiwan. Taipei: Mei Ya Inc.

Tze, P. \& Mong, W. 1977. The basic study of Chinese Bulbuls in Taiwan. Taihai Bio. J. 4: 14-18.

Wang, C. 1980. Geographic and Land of Kenting National Park. Taipei: Interior National Park Committee Press.

Zimmerman, J.L. 1971. The territory and its density dependent effect in Spiza americana. Auk 88: 591-612.

Submitted 7 July 1995; revision accepted 10 April 1996

\section{APPENDIX}

\section{Description of the measurement of 13 nest-site characteristics taken for Styan's Bulbul}

(1) Nest height above ground $(\mathrm{cm})$.

(2) Tree-nest difference $(\mathrm{cm})-$ nest tree height minus nest height.

(3) Distance to nearest leaf ( $\mathrm{cm})$-the distance to the vegetation immediately above the nest opening.

(4) Nest position index to canopy-with the intersection of nest, the shorter diameter divided by longer diameter of canopy in the cross-section of tree canopy.

(5) Distance to main trunk $(\mathrm{cm})$-distance between nest and main trunk.

(6) Distance to nearest open space ( $\mathrm{cm})$-distance between nest and the nearest edge of canopy.

(7) Distance between supporting branches ( $\mathrm{cm}$ )-mean arc distance between nest support branches, calculated as (nest circumference - sum of diameters of support branches)/number of support branches.

(8) Number of supporting branches-number of woody stems touching and/or supporting the nest, measured at the nest site.

(9) Basal area of supporting branches $\left(\mathrm{cm}^{2}\right)$.

(10) Number of nest-tree trunks-number of woody stems $\geq 2$ 
$\mathrm{cm}$ in diameter at $130 \mathrm{~cm}$ high (breast height) of the tree containing the nest.

(11) Nest-tree basal area $\left(\mathrm{cm}^{2}\right)$-measured from the diameters of tree trunks at breast helght (d.b.h.).
(12) Tree density at nest height (no./ha) - use point-quarter methods.

(13) Distance to road or building (m). 